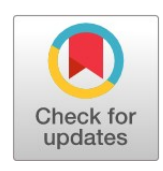

\title{
Impact of manufacturing PMI on stock market index: A study on Turkey
}

\author{
Ramazan Yanik ${ }^{1 *}$, Asfia Binte Osman ${ }^{2}$, Ozcan Ozturk ${ }^{3}$ \\ 1, 2,3 Faculty of Economics and Administrative Sciences, Ataturk University, Erzurum, Turkey
}

\author{
Keywords \\ PMI \\ Granger causality test \\ Turkey \\ Received: 9 January 2020 \\ Accepted: 12 March 2020 \\ Published: 29 June 2020
}

\begin{abstract}
Purchasing Managers' Index (PMI) is an indicator to measure the health of an economy. PMI is considered by policymakers and related bodies as it is an influential indicator for gauging the general tendency of the economy, especially GDP growth and Industrial Added Value. This study examines whether the manufacturing PMI has any influence on the stock market of Turkey or vice versa. We use the secondary sources of information collected from the official website of BIST, Turkey for Stock Index data and "investing.com" for Manufacturing PMI data. The study covers monthly data ranging from April 2015 to February 2019. We test the causality between Manufacturing PMI and BIST index by employing the Granger Causality Test. Our analysis reveals that manufacturing PMI does not granger cause the Turkish Stock Index but the Turkish Stock index or the stock market does granger cause manufacturing PMI. This study is the first attempt by the authors, which covers data of manufacturing PMI from April 2015 to February 2019 as no further data is available to be dealt with.
\end{abstract}

(C) 2020 The Author(s). Published by TAF Publishing.

\section{INTRODUCTION}

PMI, a concept for the manufacturing and service industry that serves as an indicator for the strength of an economy. Koenig et al. (2002) consider it as a treasured instrument for outlining the fitness of the manufacturing sector of the economy. Zhang, Xiao, Yang, and He (2015) define it as a wide-ranging indicator system related to fiscal monitoring published each month. The Institute for Supply Management (ISM) prepares a report every month based on the answer to the questionnaire, which is sent to the managers of supply chain department and business executives where they are asked questions about the condition of new orders, level of inventories, production, supplier deliveries and condition of employment in the firms. PMI is considered as a very renowned fiscal indicator that obtains the regular attention of the media, policymakers and other bodies who wish to get privilege in forecasting actual fiscal movements (Hsu \& Utami, 2016; Kinata, 2016; Lahiri \& Monokroussos, 2013). Harris et al. (1991) also marked it as a sensitive index for financial markets.

A number of studies have been conducted to examine the in- fluence of manufacturing PMI on GDP of several economies. Those studies emphasize the influence of PMI on GDP. Furthermore, stock market is a very strong participant in the economic system of the country as it deals with capital circulation for industries. It is expected that a change in PMI might influence the stock market and vice versa. The primary objective of this study is to measure whether manufacturing PMI has any influence on the stock market of Turkey and vice versa.

The next section provides a conceptual framework. Section 3 gives the related literature and section 4 discusses the methodology of the study and data. Section 5 provides results and discussion and section 6 accomplishes the study.

\section{Conceptual Framework of the Study}

PMI an indicator that reveals the fiscal fitness of the manufacturing sector and service sector circulated by the ISM. An article by Frale, Marcellino, Mazzi, and Proietti (2010) underlines PMI as a reference to the future direction of an economy. ISM sends a survey question to executives, asks questions about business conditions and any kind of change

\footnotetext{
*corresponding author: Ramazan Yanik
}

†email: ramazan.yanik@atauni.edu.tr 
in the business (improving, deteriorating or no change at all). It covers five basic areas; namely- new orders, level of inventories, production, supplier deliveries and the level of employment in the firms to judge the business condition. Every single area is weighted equally. PMI number ranges from 0 to 100. A PMI number beyond 50 is a sign of expansion, a PMI number underneath 50 is a sign of contraction and a number equals 50 is a sign of no change in the business condition. It is calculated as follows:

$\mathrm{PMI}=(\mathrm{A} 1 * 1)+(\mathrm{A} 2 * 0.5)+(\mathrm{A} 3 * 0)$

Where: $\mathrm{A} 1$ indicates the percentage of responses reporting an expansion, A2 indicates the percentage of responses reporting no change and $\mathrm{A} 3$ indicates the percentage of responses reporting a contraction. Number 1 is allocated for expansion, 0.5 for no change and 0 for contraction. Koenig et al. (2002) mentioned about advantages and disadvantages of PMI. Advantages are: First, Timeliness; Second, it doesn't need large revisions. Despite these, he mentioned the drawbacks of PMI. Firstly, the survey by the ISM only contains information that is accessible to the business executives in the first fifteen days of each month. Secondly, $\mathrm{PMI}$ is a diffusion index.

\section{LITERATURE REVIEW ON PMI}

We find some previous studies that analyze the impact of PMI on the GDP growth rate: Dasgupta and Lahiri (1993) have demonstrated PMI to be useful for predicting GDP changes. Similar findings also portrayed in the studies done by Banerjee and Marcellino (2006), Dasgupta and Lahiri (1992), Kauffman (1999), Koenig et al. (2002), Lindsey and Pavur (2005). Some more recent studies also provide evidence in support of the previous studies. For example, Yu and Li (2012) conducted a study on the USA using the SCC-MVGARCH model to examine the dynamic relationship between two variables; namely manufacturing PMI and growth rate. The authors found a high correlation between the variables. Studies by Clements and Hendry (2011), (Camacho \& Perez-Quiros, 2010), Evans (2005), Foroni, Marcellino, and Schumacher (2011), Frale, Marcellino, Mazzi, and Proietti (2011), Giannone, Reichlin, and Small (2008), Giannone, Modugno, Reichlin, and Small (2010), Kuzin, Marcellino, and Schumacher (2011) are some contributions in the same area. More recently, a study by Zhang et al. (2015) also propose that PMI can predict GDP.

PMI is found to have an impact on some other factors alongside the factors mentioned above.
A study by Harris et al. (1991) demonstrates that PMI has control in forecasting industrial activities in an identical interval. It demonstrates PMI as a very vibrant economic measure. Zhao and Yun (2012) also found a high relationship between Industrial Value Added and PMI in their study. They also agree to the fact that PMI can forecast Industrial Value Added.

The stock market is a strong platform to develop the capital base for institutions and creates a source of investment for the investors. It circulates a very significant portion of money in every economy, therefore, plays an active rule in assuring development for an economy. As a strong participant of the economy, its movements are expected to have a positive or negative impact on an economy too. With these motivations, some studies have investigated the relationship between PMI and stock returns. Johnson and Watson (2011) conducted a study on the U.S. economy to see whether changes in PMI can foretell stock returns. The authors conducted the study for the period ranges from Jan.1973 to Dec.2009. Using time-series regression analysis, authors provided the evidence that changes in PMI can foretell stock returns. Their study revealed an affirmative and significant relationship between any variation in PMI and successive stock returns. Those studies also revealed that smaller firms are more likely to be influenced by changes in PMI.

Despite its importance, the previous literature showing PMI and the stock market relationship is limited in the world and there is no study, to our best knowledge, on Turkey. Our study intents to contribute in the literature by filling this gap up and provide implications for other researchers and policymakers.

\section{RESEARCH METHODOLOGY Data Collection and Study Period}

This study is conducted based on Turkey. The authors used the secondary source of information. Record of stock indices have been obtained from Borsa Istanbul and PMI data has been obtained from "investing.com". Based on the availability of information monthly manufacturing PMI index started from April 2015 to February 2019 has been used to conduct the study. Monthly All Index data has been collected for the same period to measure the influence of manufacturing PMI on the stock index and vice versa. The following graphs show the month-wise data of PMI and All Index data of BIST respectively. 


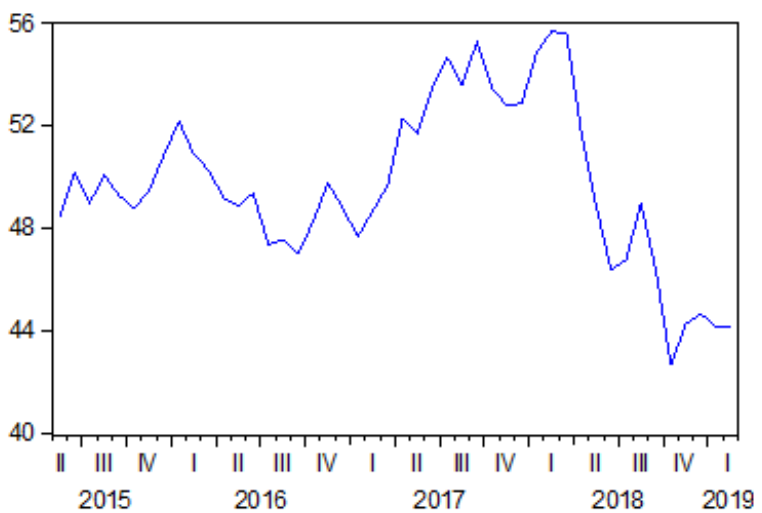

FIGURE 1. PMI

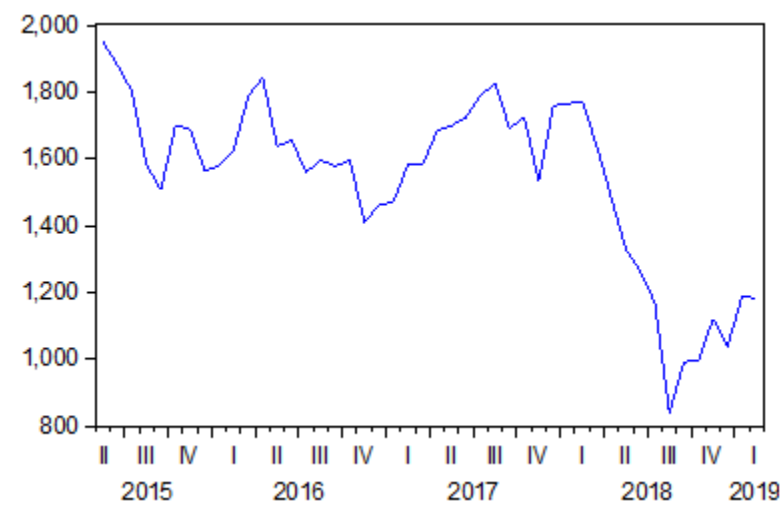

FIGURE 2. Bist

\section{Method of Study}

In the study, we employ the pairwise Granger Causality test and measure whether there exists any causal relationship between the samples; i.e., PMI and BIST All Index. First, we test the normality of the data series by doing the JarqueBera test. Once we are confirmed that our data series is a normal distribution; we need to make sure that the data is stationary. For this, we employ the Augmented DickeyFuller unit root test where we use data with the form of first differences of their logarithmic transformations and find the data is stationary. After that, we do the Pairwise Granger Causality test. In this stage, we measure if there is any causal relationship between PMI and BIST All Index by employing Standard Granger Causality test; therefore use the following regression equations keeping uniformity with the study of Obadi and Korecek (2018):

$$
\begin{gathered}
\ln \mathrm{X}=\alpha_{1}+\sum_{i=1}^{m} \beta_{i} X_{t-1}+\sum_{j=1}^{n} \lambda_{j} \ln Y_{t-j}+V_{t} \\
\ln Y=\alpha_{2}+\sum_{i=1}^{n} \gamma_{i} Y_{t-1}+\sum_{j=1}^{n} \delta_{j} X_{t-j}+\varepsilon_{t}
\end{gathered}
$$

Finally, we develop and test two null hypotheses; 1.PMI (X) does not Granger Cause BIST (Y); 2. BIST (Y) does not Granger Cause PMI $(\mathrm{X})$ in regression equations by implementing F-test to conclude.

\section{RESULTS AND DISCUSSION}

Table 1 shows the descriptive statistics of the series. Results indicate that both PMI and stock index have normal distributions while error terms have zero mean and constant variance confirmed by using the statistics of JarqueBera.

TABLE 1. Descriptive statistics

\begin{tabular}{lll}
\hline \hline & PMI & BIST \\
\hline Mean & 49.74130 & 1541.037 \\
Median & 49.35000 & 1590.570 \\
Maximum & 55.70000 & 1951.990 \\
Minimum & 42.70000 & 840.2000 \\
Std. Dev. & 3.220806 & 262.6561 \\
Skewness & -0.014626 & -0.951757 \\
Kurtosis & 2.524015 & 3.132674 \\
Jarque-Bera & 0.435884 & 6.978524 \\
Probability & 0.804172 & 0.130523 \\
Sum & 2288.100 & 70887.69 \\
Sum Sq. Dev. & 466.8115 & 3104470. \\
Observations & 46 & 46 \\
\hline \hline
\end{tabular}

Next, we conducted an Augmented Dickey-Fuller unit root test to test whether the variables are stationary at the same order as Granger causality test data to be stationary. Table 2 presents the results. Results show that both PMI and BIST variables have a unit root (non-stationary) in their level form while they are stationary in their first differenced form. Hence, both PMI and BIST stock index variables are stationary in the first difference, I (1), which leads us to conduct a pairwise Granger causality test. 
TABLE 2. Unit root test (ADF)

\begin{tabular}{lll}
\hline \hline & At Level & First Difference \\
\hline Variable & $\boldsymbol{t}$-Statistic & $\boldsymbol{t}$-Statsitic \\
\hline PMI & 3.669 & $-10.144^{*}$ \\
Bist & -3.021 & $-13.221^{*}$ \\
Augmented Dickey-Fuller test statistic & & \\
Test critical values: & 1\% level & -3.982 \\
& $5 \%$ level & -3.421 \\
& $10 \%$ level & -3.133 \\
\hline \hline
\end{tabular}

*Represents statistical significance at $1 \%$ level

Granger causality test results are presented in Table 3. Results indicate that the PMI index does not Granger cause in the stock market as we fail to reject the null hypothesis of "PMI does not Granger cause BIST". On the contrary, the null hypothesis of "BIST does not Granger cause PMI" is rejected suggesting that the financial market in Turkey has a casual effect on PMI. Results are intuitive in the sense that when stock markets perform well, companies increase their inventory level, production, employment level. Also, when the financial markets function well, the number of new orders and suppliers delivery will increase.

TABLE 3. Granger causality test results

\begin{tabular}{llll}
\hline \hline Null Hypothesis & Obs & F-Statistic & Prob. \\
\hline LNPMI does not Granger Cause LNBIST & 44 & 0.31786 & 0.7296 \\
LNBIST does not Granger Cause LNPMI & & $5.13656^{*}$ & 0.0105 \\
\hline \hline
\end{tabular}

\section{CONCLUSION AND IMPLICATIONS}

PMI is an important factor to be considered with great importance to policymakers and related bodies as it is found as an influencing factor in the GDP growth rate of an economy. The stock market is a significant part of the financial system. Therefore, any change in the stock market is supposed to have an impact (positive or negative) on the financial system, thus the economy as a whole. Measuring the impact of manufacturing PMI on the stock market will help to understand the importance of it from a different standpoint. This study aimed to investigate the relationship between manu- facturing PMI and the stock market in Turkey. Our analysis reveals that manufacturing PMI does not have a causal effect on the Turkish Stock Index or Turkish stock market but the Turkish Stock index or stock market has a causal effect on manufacturing PMI. This study is the very first attempt by the authors, which covers data of manufacturing PMI from April 2015 to February 2019 as no further data is available to be dealt with. So in the future, more studies could be conducted using a large series of data, using industry-specific data, using different indices together to measure the relationship with PMI etc.

\section{REFERENCES}

Banerjee, A., \& Marcellino, M. (2006). Are there any reliable leading indicators for US inflation and GDP growth? International Journal of Forecasting, 22(1), 137-151. doi:https://doi.org/10.1016/j.ijforecast.2005.03.005

Camacho, M., \& Perez-Quiros, G. (2010). Introducing the euro-sting: Short-term indicator of Euro area growth. Journal of Applied Econometrics, 25(4), 663-694. doi:https://doi.org/10.1002/jae.1174

Clements, M. P., \& Hendry, D. F. (2011). The oxford handbook of economic forecasting. New York, NY: OUP USA.

Dasgupta, S., \& Lahiri, K. (1992). A comparative study of alternative methods of quantifying qualitative survey responses using NAPM data. Journal of Business \& Economic Statistics, 10(4), 391-400. doi:https://doi.org/10.1080/07350015 .1992 .10509914

Dasgupta, S., \& Lahiri, K. (1993). On the use of dispersion measures from napm surveys in business cycle forecasting. Journal of Forecasting, 12(3-4), 239-253. doi:https://doi.org/10.1002/for.3980120306

Evans, M. D. (2005). Where are we now? real-time estimates of the macro economy (Tech. Rep.). National Bureau of Economic Research, California, CA.

Foroni, C., Marcellino, M. G., \& Schumacher, C. (2011). U-midas: Midas regressions with unrestricted lag polynomials. Frankfurt, Germany: Bundesbank Series.

Frale, C., Marcellino, M., Mazzi, G. L., \& Proietti, T. (2010). Survey data as coincident or leading indicators. Journal of Forecasting, 29(1-2), 109-131. doi:https://doi.org/10.1002/for.1142 
Frale, C., Marcellino, M., Mazzi, G. L., \& Proietti, T. (2011). Euromind: A monthly indicator of the Euro area economic conditions. Journal of the Royal Statistical Society: Series A (Statistics in Society), 174(2), 439-470. doi:https://doi.org/ 10.1111/j.1467-985x.2010.00675.x

Giannone, D., Modugno, M., Reichlin, L., \& Small, D. (2010). Nowcasting in real time. In 16th International Conference on Computing in Economics and Finance, Society for Computational Economics, London, UK (Vol. 13).

Giannone, D., Reichlin, L., \& Small, D. (2008). Nowcasting: The real-time informational content of macroeconomic data. Journal of Monetary Economics, 55(4), 665-676. doi:https://doi.org/10.1016/j.jmoneco.2008.05.010

Harris, E. S., et al. (1991). Tracking the economy with the purchasing managers index. California, CA: Federal Reserve Bank.

Hsu, A., \& Utami, F. (2016). Central bank intervention and stock market response. International Journal of Business and Administrative Studies, 2(5), 151-161. doi:https://doi.org/10.20469/ijbas.2.10005-5

Johnson, M. A., \& Watson, K. J. (2011). Can changes in the purchasing managers' indexforetell stock returns? An additional forward-looking sentiment indicator. The Journal of Investing, 20(4), 89-98. doi:https://doi.org/10.3905/joi.2011 .2011.1.016

Kauffman, R. G. (1999). Indicator qualities of the NAPM report on business®. Journal of Supply Chain Management, 35(1), 29-37. doi:https://doi.org/10.1111/j.1745-493x.1999.tb00234.x

Kinata, E. J. (2016). The effect of market volatility and firm size towards the difference of market reaction around stock-split announcement in Indonesia stock exchange. Journal of Administrative and Business Studies, 2(6), 304-313. doi:https:// doi.org/10.20474/jabs-2.6.5

Koenig, E. F., et al. (2002). Using the purchasing managers' index to assess the economy's strength and the likely direction of monetary policy. Federal Reserve Bank of Dallas Economic and Financial Policy Review, 1(6), 1-14. doi:https://doi.org/ 10.24149/wp1111

Kuzin, V., Marcellino, M., \& Schumacher, C. (2011). Midas vs. mixed-frequency VAR: Nowcasting GDP in the euro area. International Journal of Forecasting, 27(2), 529-542. doi:https://doi.org/10.1016/j.ijforecast.2010.02.006

Lahiri, K., \& Monokroussos, G. (2013). Nowcasting US GDP: The role of ISM business surveys. International Journal of Forecasting, 29(4), 644-658. doi:https://doi.org/10.1016/j.ijforecast.2012.02.010

Lindsey, M. D., \& Pavur, R. J. (2005). As the PMI turns: A tool for supply chain managers. Journal of Supply Chain Management, 41(1), 30-39. doi:https://doi.org/10.1111/j.1745-493x.2005.tb00182.x

Obadi, S. M., \& Korecek, M. (2018). The crude oil price and speculations: Investigation using granger causality test. International Journal of Energy Economics and Policy, 8(3), 275-284. doi:https://doi.org/10.32479/ijeep.8847

Yu, Z., \& Li, Q. (2012). Dynamic relativity study on manufacturing PMI and GDP growth rate of US. Times Finance, 11(5), 278-285.

Zhang, D., Xiao, M., Yang, X., \& He, Y. (2015). The analysis of manufacturing PMI potential trends of the US, EU, Japan and China. Procedia Computer Science, 55, 43-51. doi:https://doi.org/10.1016/j.procs.2015.07.006

Zhao, S., \& Yun, X. (2012). The relationship research between industrial added value and PMI. Economic Research Guide, 25(6), 107-110. 